Tropical Journal of Pharmaceutical Research October 2013; 12 (5): 705-710

ISSN: $1596-5996$ (print); 1596-9827 (electronic) (c) Pharmacotherapy Group, Faculty of Pharmacy, University of Benin, Benin City, 300001 Nigeria.

\title{
Methanol Extract of Codonopsis pilosula Inhibits Inducible Nitric Oxide Synthase and Protein Oxidation in Lipopolysaccharide-Stimulated Raw Cells
}

\author{
Chang-Seon Yoo and Sung-Jin Kim* \\ Department of Pharmacology and Toxicology, School of Dentistry, Kyung Hee University, Seoul, Korea 130-701 \\ *For correspondence: Email: kimsj@khu.ac.kr; Tel: +82-2-961-0868; Fax: +82-2-957-5309.
}

Received: 1 February 2013

Revised accepted: 19 June 2013

\begin{abstract}
Purpose: To evaluate the mechanism of antioxidant activity of the methanol extract of Codonopsis pilosula. Methods: Anti-oxidative properties were assessed by measuring free radical scavenging activity, nitric oxide (NO) levels, protein oxidation and reducing power, while the mechanism of antioxidative effect of Codonopsis pilosula extract was determined by measuring iNOS and COX-2 expression in lipopolysaccharide (LPS)-stimulated raw cells.

Results: Codonopsis pilosula extract (CPE) exerted significant DPPH free radical and NO-scavenging activities. Protein oxidation was decreased by $30 \%$ by the CPE $(1 \mathrm{mg} / \mathrm{ml})$. The extract $(1 \mathrm{mg} / \mathrm{ml})$ enhanced reducing power 16-fold (compared with control). LPS-induced production of iNOS was significantly inhibited by the extract (60\%), suggesting that it inhibits NO production by suppressing iNOS expression. However, LPS-induced production of COX-2 was not significantly $(p<0.05)$ inhibited by the extract. The levels of total phenolics, total flavonoids, and total anthocyanin in CPE were 0.38, 2.10, and $2.47 \mathrm{mg} / \mathrm{g}$, respectively.

Conclusion: These results suggest that CPE exerts marked antioxidant activity via inhibition of iNOS and protein oxidation.
\end{abstract}

Keywords: Codonopsis pilosula, Lipopolysaccharide, Cyclooxygenase-2 (COX-2), Free radicals, Inducible nitric oxide synthase (iNOS), Nitric oxide (NO)

Tropical Journal of Pharmaceutical Research is indexed by Science Citation Index (SciSearch), Scopus, International Pharmaceutical Abstract, Chemical Abstracts, Embase, Index Copernicus, EBSCO, African Index Medicus, JournalSeek, Journal Citation Reports/Science Edition, Directory of Open Access Journals (DOAJ), African Journal Online, Bioline International, Open-J-Gate and Pharmacy Abstracts

\section{INTRODUCTION}

Codonopsis pilosula has been widely used as an Oriental medicine. It has been found tocontain a wide variety of phytochemicalsincluding hesperidin, $\beta$-sitosterol, loberyolinin, $\beta$ daucosterol [1], triterpenyl esters, codonopilates A-C [2], phenylpropanoid glycosides [3] and $\beta$ carbioline alkaloid [4]. Historically, it has long been used for the treatment of digestive disorders such as indigestion, loose stool, fatigue and pulmonary insufficiency including shortness of breath, coughing [5]. Recent studies also showed that Codonopsis pilosula is capable of ameliorating peptic ulcer, promoting bowel movement, enhancing learning and memory, and increasing red blood cells and hemoglobin [6].

Imbalance between reactive oxygen species (ROS) and anti-oxidative system causes oxidative stress. The production of ROS such as superoxide anion, hydrogen peroxide, and hydroxyl radical occurs via mitochondrial respiratory chain [7]. Nitric oxide (NO) synthesized by iNOS in response to ROSinduced oxidative stress play important roles in many diseases such as cancer, diabetes, 
cardiovascular diseases, neurodegenerative disease and oral diseases. COX-2 (cyclooxgenase-2) is known to produce prostaglandins which are essential mediators for inflammatory reaction in the body, and it is regarded as an important molecular target of antioxidative drug development. The objective of the present study was to determine whether Codonopsis pilosula extract has anti-oxidative activities and whether iNOS and COX-2 are involved in its anti-oxidant actions.

\section{EXPERIMENTAL}

\section{Preparation of plant extracts}

Authentic samples of Codonopsis pilosula collected during October, 2010 were purchased from Kyung-Dong Oriental Market in Seoul. They were authenticated by Emeritus Professor Chang-Soo Yok, Department of Oriental Pharmacy, College of Pharmacy, Kyung Hee University, Seoul, Korea. A voucher specimen (no. 8N009) was deposited at the herbarium of the Department of Pharmacology and Toxicology, School of Dentistry, Kyung Hee University, Seoul, Korea. The plant $(100 \mathrm{~g})$ was cut into small pieces and extracted 3 times with $300 \mathrm{ml}$ of $70 \%$ methanol for $3 \mathrm{~h}$, The resultant extract was concentrated by a rotary evaporator and dried by a freeze-dryer.

\section{Reagents and materials}

The iNOS and COX-2 antibodies were purchased from Cell Signaling and Santa Cruz Biotechnology Co, respectively while ECL kit was purchased from Amersham Co., USA. All other reagents were purchased from Sigma Co., USA. Cell culture media were purchased from Gibco Co.

\section{Free radical scavenging activity}

Free radical scavenging activity was measured by evaluating reduction reactions of DPPH radical in the presence of hydrogen-donating antioxidants [8] and NO. DPPH (Fluka Chemie, Buchs, Switzerland) solutions show a peak absorption at $515 \mathrm{~nm}$ and present deep violet color. Briefly, Codonopsis pilosula extract $(0.01 \mathrm{mg} / \mathrm{ml}, 0.1 \mathrm{mg} / \mathrm{ml}, 1 \mathrm{mg} / \mathrm{ml})$ was dissolved in $1 \mathrm{ml} \mathrm{MeOH}$, mixed with $1 \mathrm{ml}$ DPPH solution at room temperature and optical density measured at $515 \mathrm{~nm}$ (BioRad Model 550). NO generated from sodium nitroprusside (SNP) was measured using Griess reagent at $540 \mathrm{~nm}$.

Briefly, Codonopsis pilosula extract $(0.01,0.1$ or, $1 \mathrm{mg} / \mathrm{ml}$ ) in a volume of $100 \mathrm{ul}$ was added to 200 ul SNP $(10 \mathrm{mM}$ ) and $1.8 \mathrm{ml}$ of phosphate buffer $(\mathrm{pH}$ 7.4). The reaction mixture was allowed to incubate at $37 \stackrel{\circ}{\circ} \mathrm{C}$ for $3 \mathrm{~h}$. Thereafter, $1.0 \mathrm{ml}$ of the reaction mixture was mixed with $0.5 \mathrm{ml}$ of Greiss reagent and the absorbance measured at $540 \mathrm{~nm}$.

\section{Determination of protein oxidation}

The effect of Codonopsis pilosula extract on protein oxidation was determined as previously described [9]. The reaction mixture $(1.2 \mathrm{~mL})$ in phosphate buffer $(20 \mathrm{mM}, \mathrm{pH} 7.4)$, containing the Codonopsis pilosula extract, bovine serum albumin $(20 \mathrm{mg} / \mathrm{mL}), \mathrm{FeCl}_{3}(400 \mu \mathrm{M}), \mathrm{H}_{2} \mathrm{O}_{2}$ (1 $\mathrm{ml}, 3 \mathrm{mM})$, and ascorbic acid $(400 \mu \mathrm{M})$ was incubated at $37{ }^{\circ} \mathrm{C}$ for $1 \mathrm{~h}$. Dinitrophenyl hydrazine $(20 \mathrm{mM}$ in $2 \mathrm{~N} \mathrm{HCl})$ and trichloroacetic acid $(20 \% \mathrm{w} / \mathrm{v})$ were added to the reaction mixture and subjected to centrifugation at $650 \mathrm{~g}$ for $10 \mathrm{~min}$. The supernatant was discarded and the resulting pellet was washed three times with $2.0 \mathrm{~mL}$ of $\mathrm{EtOH} / \mathrm{EtOAc}(1: 1)$ solution, dissolved in $2.0 \mathrm{~mL}$ of $6 \mathrm{M}$ guanidine- $\mathrm{HCl}(\mathrm{pH} \mathrm{6.5)}$ and monitored spectrophoymetrically at $370 \mathrm{~nm}$.

\section{Determination of reducing power}

Reducing power was measured by Oyaizu method [10]. Codonopsis pilosula extract (2.5 $\mathrm{ml}$, in $0.2 \mathrm{M}$ phosphate buffer, $\mathrm{pH} 6.6$ ) was placed in $2.5 \mathrm{ml}$ of potassium ferricyanide (10 $\mathrm{mg} / \mathrm{ml}$ ) solution and incubated for $15 \mathrm{~min}$ at $30^{\circ} \mathrm{C} ; 2.5 \mathrm{ml}$ of trichloroacetic acid $(100 \mathrm{mg} / \mathrm{ml})$ was added to the reaction mixture. To $2.5 \mathrm{ml}$ of the mixture , $2.5 \mathrm{ml}$ of distilled water and $0.5 \mathrm{ml}$ of ferric chloride $(1.0 \mathrm{mg} / \mathrm{ml})$ were added. Then, optical density was read at $700 \mathrm{~nm}$.

\section{Cell culture}

Murine RAW 264.7 macrophage cells were cultured in Dulbecco's modified Eagle's Medium (DMEM) (Gibco BRL, Grand island, NY) with $10 \%$ heat-inactivated fetal bovine serum in $5 \%$ humidified $\mathrm{CO}_{2}$ atmosphere at $37^{\circ} \mathrm{C}$.

\section{Measurement of nitric oxide}

The Raw cells were cultured with DMEM and $10 \%$ FBS. NO was measured with cell supernatant as nitrite and nitrate. The safe form of nitrite after being reduced to nitrate was measured using Greiss reagent (Sigma, USA). A total of $2 \times 10^{6}$ Raw cells were seeded into a 6 well plate for $24 \mathrm{~h}$ before the extract treatment. and the cells were incubated with the samples at different concentrations (1.0, 0.1 , and 0.01 $\mathrm{mg} / \mathrm{ml}$ ) Four hours later, lipopolysaccharide (LPS, final concentration $10 \mathrm{ug} / \mathrm{ml}$ ) was put into 
all wells except for the well for the control group to stimulate the cells. The amount of NO generated was determined as nitrite, a major stable product of $\mathrm{NO}$, by the Griess reagent assay. The absorbance was measured spectrophotometrically $18 \mathrm{~h}$ later at $540 \mathrm{~nm}$.

\section{Measurement of iNOS and COX-II expression}

Raw cells were cultured with DMEM and $10 \%$ FBS. When the cells reached confluence, the DMEM culture medium was removed and replaced by the Eagle's Minimum Essential Medium (EMEM) culture medium which is a serum-free culture medium and then the cells were treated with Codonopsis pilosula extracts and cultured for $24 \mathrm{~h}$. The cells were washed two times with PBS and scraped into a $10 \mathrm{mM}$ Tris- $\mathrm{HCl}$ buffer, $\mathrm{pH} 7.4$, containing $50 \mathrm{mM} \mathrm{NaCl}$, $5 \mathrm{mM}$ EDTA, $30 \mathrm{mM} \mathrm{NaF}, 0.1 \mathrm{mM} \mathrm{Na}_{3} \mathrm{VO}_{4}, 1 \%$ triton X-100, $0.5 \% \mathrm{NP}-40,1 \mathrm{ug} / \mathrm{ml}$ leupetin, and $1 \mathrm{ug} / \mathrm{ml}$ aprotinin. The cells were disrupted by passing them 5 times through a 1-ml tuberculin syringe. The cell lyaste was subjected to centrifugation at $10,000 \times g$ for $10 \mathrm{~min}$ and the supernatant used for Western blot analysis. The protein content of the soluble fraction was assessed by the method of Bradford [11]. After addition of sample loading buffer, equivalent amounts of protein samples (50ug/lane) were electrophoresed on a $10 \%$ sodium dodecyl sulfate denaturing polyacrylamide slab gels (SDS-PAGE) and subsequently transferred to nitrocellulose transfer membrane (Whatman PROTRAN) for $1 \mathrm{~h}$ at $100 \mathrm{~V}$ (constant) as described by Towbin et al [12]. The membrane was incubated in fresh blocking buffer $(0.1 \%$ Tween 20 in Tris-buffered saline, TTBS, pH 7.4, containing $5 \%$ non fat dried milk) at room temperature for $60 \mathrm{~min}$ and then probed with the iNOS (1:1000), COX-II (1:2000), GAPDH $(1: 1000)$ antibodies overnight in blocking buffer at $4^{\circ} \mathrm{C}$. The membrane was washed three times for 10 min each using TTBS. After that it was incubated in the appropriate Horse radish peroxidase (HRP)-conjugated secondary antibody (1:1000 for iNOS and GAPDH; 1:2000 for COX-II) at room temperature for another $2 \mathrm{~h}$ and washed again three times in TTBS buffer. The membrane was developed using the enhanced chemiluminescence reagents (ECL) for $5 \mathrm{~min}$ according to the manufacturer's instructions and was exposed to Amersham Hyperfilm ECL (GE Healthcare Limited, UK). The results obtained from the immunoblot assay were calculated using IMAGEJ imaging software (NIH, USA) as the integrated density.

\section{Measurement of total phenolics}

Total phenolic content was measured spectrophoyometrically by Folin-Ciocalteau method at $725 \mathrm{~nm}$ [13]. The extract (200 ul, 2 $\mathrm{mg} / \mathrm{ml}$ ) was mixed with $1.8 \mathrm{ml}$ water and $200 \mathrm{ul}$ of Follin-Ciocalteu reagent. After $3 \mathrm{~min}, 400 \mathrm{ul}$ of Sodium carbonate $(35 \%, \mathrm{w} / \mathrm{v})$ and $1.4 \mathrm{ml}$ of water were added to the mixture and followed by the measurement of absorbance at $725 \mathrm{~nm}$. Gallic acid was used as a standard for phenolic compounds and the phenolic concentration was calculated using a gallic acid standard calibration curve. The total phenolic content was expressed as the gallic acid equivalent (mg gallic acid/g extract).

\section{Measurement of total flavonoids}

Total flavonoids was measured by the method of Miliauskas et al. [14] and was expressed as the rutin equivalent (mg rutin acid/g extract) using rutin as a standard flavonoid; $200 \mathrm{ul}$ of the extract $(1 \mathrm{mg} / \mathrm{ml}$ ) was mixed with $200 \mathrm{ul}$ of aluminum trichloride in ethanol $(20 \mathrm{mg} / \mathrm{ml})$ and diluted to $5 \mathrm{ml}$. After incubation for $40 \mathrm{~min}$ at $20{ }^{\circ} \mathrm{C}$, the optical density was read spectrophotometrically at $415 \mathrm{~nm}$.

\section{Measurement of total anthocyanin}

Total anthocyanin was measured as described previously [15]. The extract (2 mg) was dissolved in $3 \mathrm{ml}$ of acetate buffer $(25 \mathrm{mM}, \mathrm{pH}$ 4.5) and the optical density was measured at $520 \mathrm{~nm}$. The content of anthocyanin was expressed as kuromanin equivalent (mg kuromanin/g extract).

\section{Statistical analysis}

All data were expressed as mean \pm SEM. Statistical analysis was performed using GraphPad Prism 5 by one-way ANOVA followed by Tukey's multiple comparison test. $P<0.05$ was considered as significant.

\section{RESULTS}

DPPH free radicals were decreased approximately $7 \%$ by $0.01 \mathrm{mg} / \mathrm{ml}$ of Codonopsis pilosula extract and by about $3 \%$ at $0.1 \mathrm{mg} / \mathrm{ml}$, compared to control. At a concentration of 1.0 $\mathrm{mg} / \mathrm{ml}$, DPPH free radicals decreased by $19 \%$ (Figure 1).

Taurine did not show any significant effect on DPPH scavenging activity whereas butylated hydroxytoluene (BHT) caused $46 \%$ reduction of $\mathrm{DPPH}$ free radical levels. The extract also 
decreased the level of NO by 6,6 and $13 \%$ at extract concentrations of $0.01,0.1$, and $1 \mathrm{mg} / \mathrm{ml}$, respectively, while taurine decreased $\mathrm{NO}$ levels by 6 and $4 \%$ at $0.01 \mathrm{mg} / \mathrm{ml}$ and $0.1 \mathrm{mg} / \mathrm{ml}$, respectively (Figure 2 ).

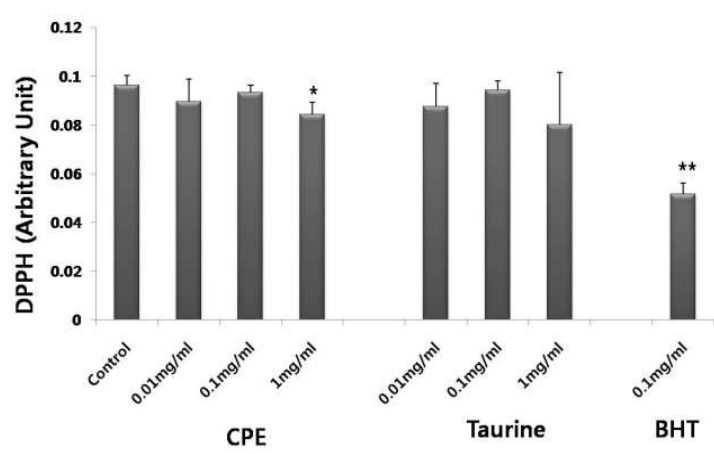

Fig 1: DPPH radical scavenging activity of Codonopsis pilosula extract. Note: value are mean \pm SEM; ${ }^{*} p<0.05,{ }^{* *} p<0.01$

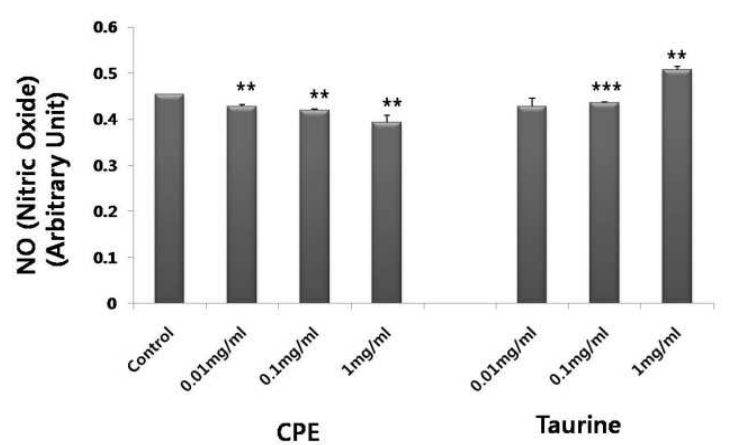

Fig 2: Nitric oxide (NO) radical scavenging activity of Codonopsis pilosula extract. Note: value are mean \pm SEM; ${ }^{* \star} p<0.01,{ }^{* \star *} p<0.001$

Protein oxidation was also decreased by 30 and $40 \%$ at concentrations of $0.1 \mathrm{mg} / \mathrm{ml}$ and $1 \mathrm{mg} / \mathrm{ml}$, respectively, the extract (Figure 3 ).

Table 1: Antioxidant components of Codonopsis pilosula extract

\begin{tabular}{ll}
\hline CP extract & Mean \pm SEM \\
\hline Phenolics (gallic acid, ug/mg) & $0.376 \pm 0.118$ \\
Anthocyanins (kuromanin, ug/mg) & $2.47 \pm 0.753$ \\
Flavonoids (rutin, ug/mg) & $2.100 \pm 0.265$
\end{tabular}

The extracts stimulated the reducing power by 6.7-fold and 16.1-fold (compared to control) at 0.1 and $1 \mathrm{mg} / \mathrm{ml}$, respectively, whereas taurine stimulated it by 1.8 -fold at $1 \mathrm{mg} / \mathrm{ml}$. (Figure 4 ).

The amount of nitric oxide production was markedly increased (5.0-fold over basal) when the Raw cells were treated with LPS to activate the macrophages whereas when the cells were pretreated with the Codonopsis pilosula extract, NO production was significantly decreased by $4.5,34.5$, and $52.7 \%$ in response to $0.01,0.1$, and $1 \mathrm{mg} / \mathrm{ml}$ extract, respectively, compared to LPS-induced stimulation (Figure 5).

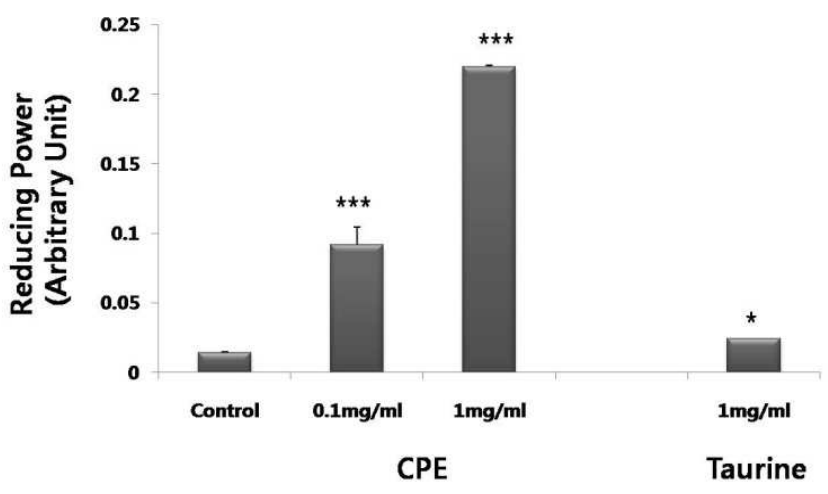

Fig 3: Reducing power of Codonopsis pilosula extract. Note: Values are mean \pm SEM; ${ }^{*} p<0.05$, ${ }^{* * *} p<0.001$

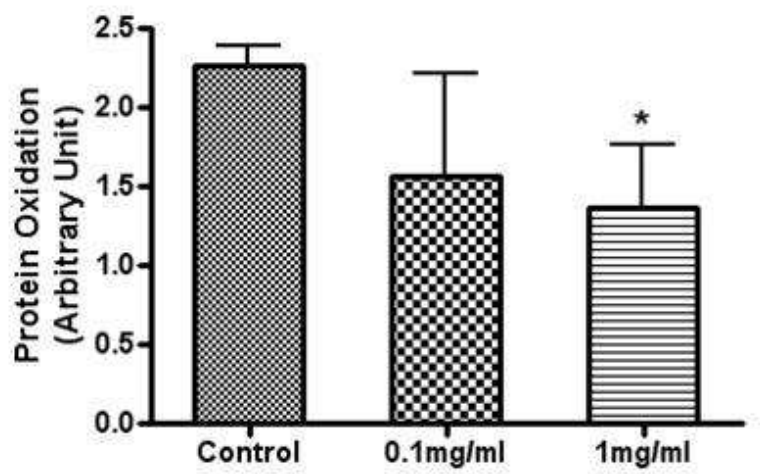

Fig 4: Effect of Codonopsis pilosula extract on protein oxidation. Note: Values are mean \pm SEM; ${ }^{*} p<0.05$

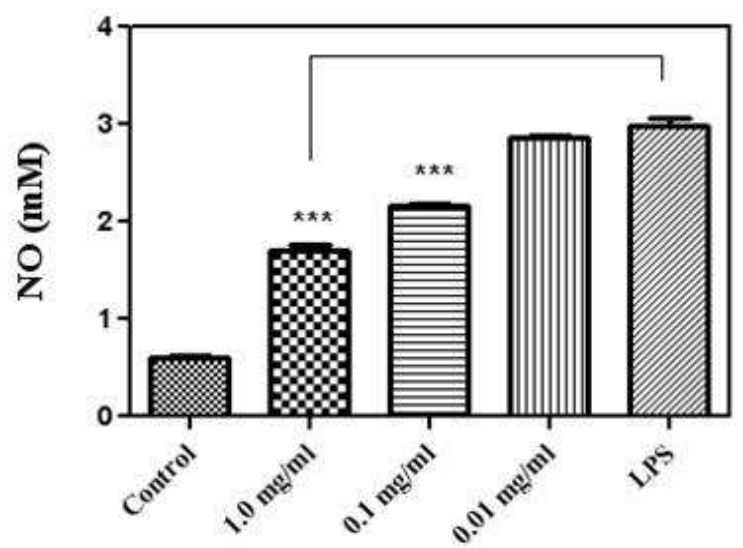

Fig 5: Inhibition of nitric oxide (NO) by Codonopsis pilosula extract. Note: Values are mean $\pm \mathrm{SEM} ;{ }^{* * *} p$ $<0.001$

When LPS was administered to the Raw cells, the expression of iNOS increased by 9.6-fold over basal. On the other hand, when the cells were pretreated with Codonopsis pilosula extract, iNOS expression levels were markedly decreased by 11,13 , and $82 \%$ in response to concentrations of $0.01,0.1$, and $1 \mathrm{mg} / \mathrm{ml}$, respectively, compared to the LPS-induced stimulation (Figure 6). 


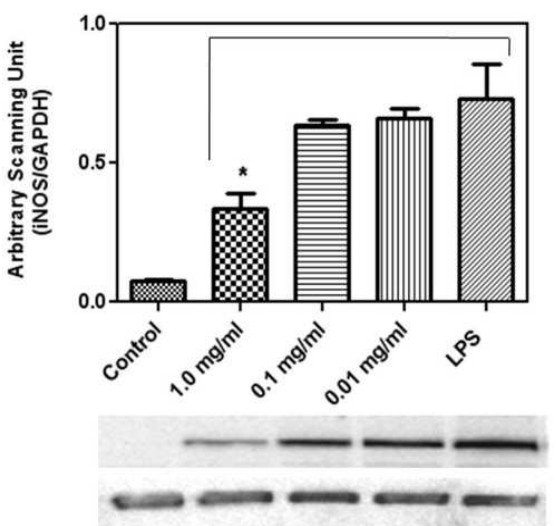

iNOS

GAPDH

Fig 6: Effect of Codonopsis pilosula extract on LPSinduced iNOS induction. Note: value are mean \pm SEM; * $p<0.05$,

The Codonopsis pilosula extract had little or no effect on the expression of LPS-induced COX-2 (Figure 7).

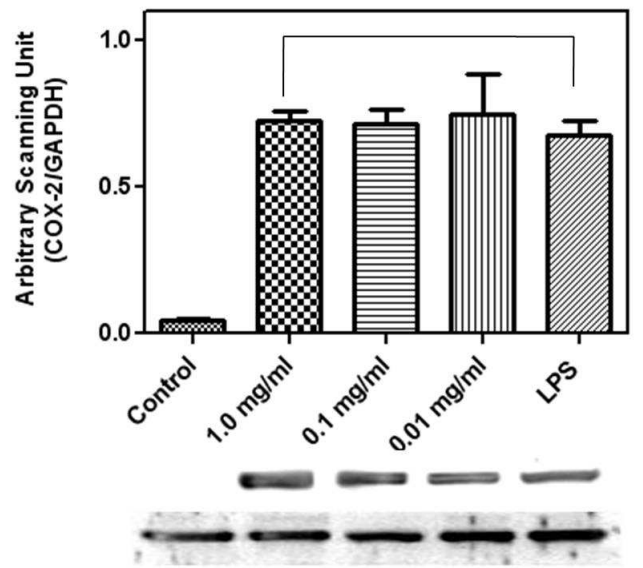

COX-2

GAPDH

Fig 7: Effect of Codonopsis pilosula extract on LPSinduced COX-II induction. Note: Values are mean \pm SEM

When antioxidant components present in the Codonopsis pilosula extract was analyzed, total phenolics, total flavonoids, and total anthocyanin were determined as $0.38,2.10$, and $2.47 \mathrm{mg} / \mathrm{g}$, respectively (Table 1 ).

\section{DISCUSSION}

It has been widely accepted that oxidative stress plays an important role in the development of many diseases such as cancer, diabetes, Parkinson's disease, cardiovascular diseases, and periodontal diseases [16-18].

Reactive oxygen species (ROS) generated by oxidative stress like smoking, ultraviolet rays, stress, and aging are important signaling molecules in the cell $[16,17]$. They damage lipids, proteins and nucleic acids, thereby promoting many diseases and aging. DPPH free radical-removing and nitric oxide scavenging properties of Codonopsis pilosula extract have been demonstrated in this study. In addition, the extract showed strong reducing power relative to control. These results suggest that the extract has the ability to neutralize various reactive oxygen species generated by oxidative stress. For instance, the marked reducing power of the extract could be beneficial in removing toxic peroxides generated by oxidative stress.

Oxidative stress causes protein oxidation and thereby disturbing the normal protein structure and function. Metabolism-related proteins, mitochondrial proteins, chaperones and protein members of ubiquitin-proteasome system are known to be sensitive to oxidation [18]. Protein oxidation is associated with human degenerative diseases, supranuclear palsy and age-related diseases [19]. Interestingly, it has been reported that oxidative stress could inactivate many proteins such as $\mathrm{Cu}, \mathrm{Zn}$ superoxide dismutase [20]. Taking these into consideration, Codonopsis pilosula extract may be beneficial to prevent oxidative damages to proteins.

NO has been implicated in pain and tissue damage [21]. Oxidative stress is essential in the progress of periodontal diseases while antioxidants such as flavonoids or vitamin $\mathrm{C}$ can prevent such progresses. $\mathrm{NO}$ is an important signaling molecule responsible for various inflammatory responses in vivo $[22,23]$. It is generated by the activation of iNOS enzyme induced by inflammation. Plant extracts with the ability to regulate iNOS and COX-II also have anti-inflammatory actions [24-26]. In the present study, it has been shown that the Codonopsis pilosula extract significantly reduces the concentration of NO generated by LPS in the Raw cells and shows strong inhibition of iNOS expression. In contrast, COX-II was not affected by the Codonopsis pilosula extract. These results suggest that the anti-oxidative action of the Codonopsis pilosula extract may be mediated by the inhibition of the iNOS-NO system, rather than COX-II enzyme.

Plant extracts with antioxidative effects are known to contain phenolics, anthocyanin, and flavonoids [27]. The Codonopsis pilosula extract contains significant amounts of phenolics including anthocyanins and flavonoids, suggesting that these components may be major contributors to the iNOS inhibitory action of the extract.

\section{CONCLUSION}

We propose that Codonopsis pilosula extract could exert antioxidant effect due to the 
inhibition of iNOS, and scavenging of NO and free radical, as well as inhibition of protein oxidation.

\section{REFERENCES}

1. Qi HY, Wang R, Liu Y, Shi YP. Studies on the chemical constituents of Codonopsis pilosula. Zhong Yao Cai 2011; 34: 546-548.

2. Wakana D, Kawahara N, Goda Y. Three new triterpenyl esters, codonopilates A-C, isolated from Codonopsis pilosula. J Nat Med 2011; 65: 18-23.

3. Mizutani K, Yuda M, Tanaka O, Saruwatari Y, Jia MR, Ling YK, Pu XF. Tangshenosides I and II from Chun-Dangshen, the root of Codonopsis tangshen Oliv. Chem Pharm Bull 1998; 36: 2726-2729.

4. Liu T, Liang W, Tu G. Perlolyrine: a $\beta$-carboline alkaloid from Codonopsis pilosula. Planta Medica 1988; 54: $472-473$

5. Xu QP. Ed. Pharmacology of Chinese Herbs (Chinese): Guizhou Science and Technology Publishing Company, Guiyang, Guozhou Province, P.R. China, 1994

6. Singh B, Song H, Liu XD, Hardy M, Liu GZ, Vinjamury S, Martirosian CD. Dangshen (Codonopsis Pilosula) and Bai Guo (Gingko Biloba) enhance learning and memory. Alternative Therapies 2004; 10: 5256.

7. Fridovich I. The biology of oxygen radicals. Science 1978; 201: 875-880.

8. Brand-Williams W, Cuvelier ME, Berset C. Use of a free radical method to evaluate antioxidant activity. Lebenson Wiss Technol 1995; 28: 25-30.

9. Levine RL, Garland D, Oliver CN, Amici A, Climent I, Lenz $A G, \quad A h z$ BW, Shaltiel S, Stadtman ER. Determination of carbonyl content in oxidatively modified proteins. Methods Enzymol 1990; 186: 464-478.

10. Oyaizu M. Studies on products of browning reaction: Antioxidative activities of products of browning reaction prepared from glucosamine. Jpn J Nutr 1986; 44: 307-314.

11. Bradford MM. A rapid and sensitive method for the quantitation of microgram quantities of protein utilizing the principle of protein-dye binding. Anal Biochem 1976; 722: 248-254.

12. Towbin H, Staehelin J,Gordon J. Electrophoretic transfer of proteins from polyacrylamide gels to nitrocellulose sheets: procedure and some application. Proc Natl Acad Sci USA 1979; 76 . 4350-4354.

13. Singleton VL, Rossi JA. Colorimetry of total phenolics with phosphomolybdic-phosphotungstic reagents. Am J Enol Vitic 1965; 16: 144-158.

14. Miliauskasa G, Venskutonis $P R$, van Beekb TA. Screening of radical scavenging activity of some medicinal and aromatic plant extracts. Food Chem 2004; 85: 231-237.
15. Piccolella S, Fiorentino A, Pacifico S, D'Abrosca B, Uzzo $P$, Monaco P. Antioxidant properties of sour cherries (Prunus cerasus L.): Role of colorless phytochemicals from the methanolic extract of ripe fruits. J Agric Food Chem 2008; 56: 1928-1935.

16. Kim BJ, Kim JH, Kim HP, Heo MY. Biological screening of 100 plant extracts for cosmetic use (II): Antioxidative activity and free radical scavenging activity. Int J Cosmet Sci 1997; 19: 299-307.

17. Evereklioglu C, Er H, Doganay S, Cekmen M, Turkoz Y, Otlu B, Ozerol E. Nitric oxide and lipid peroxidation are increased and associated with decreased antioxidant enzyme activities in patients with agerelated macular degeneration. Doc Ophthalmol 2003; 106: 129-136.

18. Avery SV. Molecular targets of oxidative stress. Biochem J 2011; 434: 201-210.

19. Martínez A, Portero-Otin M, Pamplona R, Ferrer I. Protein targets of oxidative damage in human neurodegenerative diseases with abnormal protein aggregates. Brain Pathol $2010 ; 20$ : 281-297.

20. Costa WMV, Amorim MA, Quintanilha A, MoradasFerreira P. Hydrogen peroxide-induced carbonylation of key metabolic enzymes in Saccharomyces cervisiae: the involvement of the oxidative stress response regulators Yap 1 and Skn7. Free radical Biol. 2002; 33: 1507-1515.

21. Ndengele MM, Cuzzocrea S, Esposito E, Mazzon E, Di Paola R, Matuschak GM, Salvemini $D$. Cyclooxygenases 1 and 2 contribute to peroxynitrite-mediated inflammatory pain hypersensitivity. FASEB J. 2008; 22: 3154-64.

22. Condoner-Frnach P, Travarez-Alonso S, Murria-Estal $R$ Megias-Vericat J, Tortajada-Girbes M, AlonsoIglesias E. Nitric oxide production is increased in severely obese children and related to markers of oxidative stress and inflammation. Atheroscrelosis, 2011. Epub ahead of print.

23. Conforti F, Menichini F. Phenolic compounds from plants as nitric oxide production inhibitors. Curr. Med. Chem. 2011; 18: 1137-1145.

24. Handunnetti $S M$, Kumara RR, Deraniyagala $S A$, Ratnasooriya WD. Anti-inflammatory activity of Ixora coccinea methanolic leaf extract. Pharmacogn Res 2009; 1: 80-90.

25. Gambhire MN, Wankhede SS, Juvekar AR Antiinflammatory activity of aqueous extract of Barleria cristata leaves. J Young Pharm 2009; 1: 220-224.

26. Kumar D, Kumar S, Singh J, Narender, Rashmi, Vashistha $B D$, et al. Free radical scavenging and analgesic activities of Cucumis sativus $L$. fruit extract. J Young Pharm 2010; 2: 365-368.

27. Kähkönen MP, Hopia Al, Vuorela HJ, Rauha JP, Pihlaja $K$, Kujala TS, Heinonen M. Antioxidant Activity of Plant Extracts Containing Phenolic Compounds. J. Agric. Food. Chem. 1999; 47: 3954-3962 